\title{
Bovies, Burr Holes, and Blood Clots: Recollections of My Start in Neurosurgery: 1956-65
}

\author{
R. Graham Vanderlinden
}

Keywords: Canadian Neurosurgery, Dwight Parkinson, Charles Drake

doi:10.1017/cjn.2015.346

Can J Neurol Sci. 2016; 43: 434-442

\section{Preamble}

Dr. Graham Vanderlinden was a staff neurosurgeon at Toronto Western Hospital from 1967 until 1987, at which time he and Dr. Hart Shutz (another neurosurgeon and colleague at Toronto Western Hospital back then) moved to open a new neurosurgical unit at the Mississauga Hospital (now part of the Trillium Health Centre). Graham continued his general neurosurgical practice in Mississauga until 2001 and, following that, directed his pain clinic (and performed pain treatment procedures) until 2011. Graham has a particular interest in pain, starting in the laboratory in the late 1960s and then throughout his entire clinical career. He was one of the relatively few in Canada to perform percutaneous $\mathrm{C} 1-\mathrm{C} 2$ cordotomies (spinothalamic tractotomies), one of the first to implant spinal cord stimulators, to percutaneously denervate spinal facet joints (radiofrequency "facet rhizotomy"), and to treat tic douloureux with both percutaneous balloon compression of the trigeminal ganglion and open microvascular decompression of the brainstem root entry zone (and the list goes on). He kept meticulous records of his work and published continuously on many of these subjects. He avoided brain stimulation because, as he put it, "Ron Tasker was covering that area so brilliantly."

Graham ("Van" to his residents) was a wonderful mentor and friend to generations of University of Toronto neurosurgical trainees. Always cheerful, fun, and optimistic, Graham was trusting and generous in allowing us to help manage his patients. He knew that we would make mistakes, but insisted only we be honest about them. Graham was an antidote to our daily struggles as neurosurgical trainees. And he tells great stories with a remarkable memory for detail, as you will soon see.

Van's old residents will hear his voice when they read the written words that follow, but I think everyone will enjoy these wonderful and historic recollections.

\section{-Max Findlay, University of Alberta}

\section{Part 1: First Neurosurgical Experiences}

After obtaining my medical degree from the University of Manitoba (Figure 1), I completed the requisite "rotating internship" at the Winnipeg General Hospital in 1956-57. Dr Dwight Parkinson was head of the division of neurosurgery; on my first day on his service, December 1, 1956, I was scheduled to be his only assistant for a craniotomy. Little did I realize at the time that the case was destined to become part of medical history. ${ }^{1}$

The patient had a carotid-cavernous fistula, and, in an effort to relieve his symptoms, Dr Parkinson had already ligated both the right and left external carotid arteries and then the right internal carotid artery in the neck. The planned operation that day was to clip the internal carotid artery within the skull and beyond the fistula, thus "trapping" the fistula and hoping to obliterate it completely. My job was to step on the Bovie (bipolar cautery) pedal when directed to do so and provide as much assistance as my state of ignorance allowed.

The tension in the operating room (OR) was palpable. Dr Parkinson had a reputation for being a demanding, no-nonsense surgeon, tyrannical in the operating suite and uncompromising in his rigorous standards. His bearing was that of a drill sergeant with a straight back, straight mouth, and a military brush cut. Dwight was an American but had been recruited as Manitoba's first neurosurgeon, ${ }^{2}$ having trained at the Mayo Clinic. World War II had interrupted his neurosurgical training, and he served with distinction as a Battalion Surgeon in Europe, rising to the rank of Captain and receiving two bronze stars. His main hobby, however, was figure skating, and through hard work and discipline, he excelled in the sport right into adulthood and even became a judge at skating competitions (Figure 2). ${ }^{3}$

The operation went well apart from much bleeding. When the skull was exposed, blood spurted out of emissary veins and arched onto the floor a couple of feet away. I was amazed and terrified, but Dr. Parkinson controlled the blood bath with bone wax and proceeded to put in burr holes with a hand-held Hudson brace. The exposed dura resembled a basket of grapes with all the dural vessels engorged like hemorrhoids. Finally, the dura was opened and Dr. Parkinson began the careful dissection along the floor of the frontal fossa. I was unable to see anything, but when finally Dr. Parkinson applied the clip to the supraclinoid carotid artery, he jumped up and down shouting "I did it, I did it, I did it!"

\footnotetext{
From the University of Toronto, Toronto, Ontario, Canada (retired).

Received March 26, 2015. Final Revisions Submitted September 6, 2015. Correspondence to: R. Graham Vanderlinden, 11823B Loyalist Parkway, RR 4, Picton, Ontario, Canada K0K 2T0. Email: graham.vanderlinden@sympatico.ca
} 
Although such behaviour was startling, it served the purpose of breaking the tension in the OR, allowing a much appreciated relaxed atmosphere for the closure.

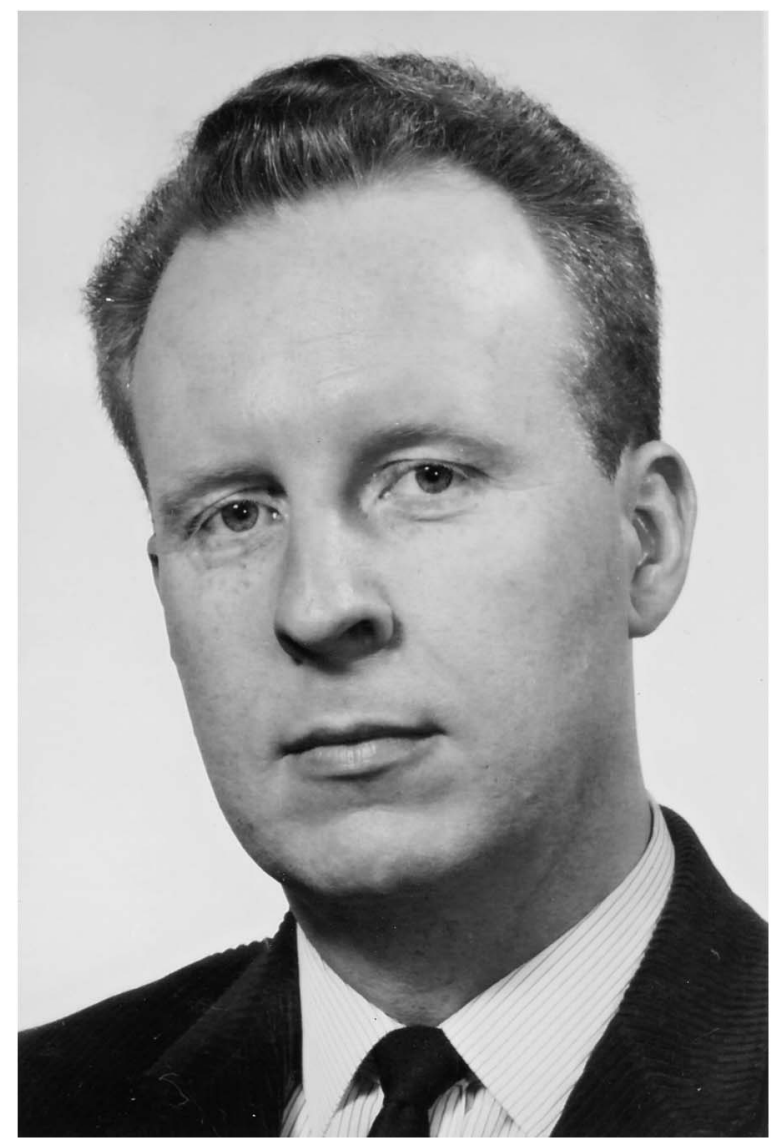

Figure 1: R. Graham Vanderlinden's graduation portrait picture from medical school, University of Manitoba, 1957.
The patient survived, his bruit and exophthalmus subsided, and it seemed as if the operation was successful. I learned much later that all his symptoms recurred. Dr. Parkinson faced this disappointment with determination and sought the answer in the anatomy laboratory, where he dissected 200 cavernous sinuses. He discovered an area in the lateral wall of the cavernous sinus that could be opened without injury to cranial nerves located within it, and through which a fistula might be clipped directly, rather than "trapped" as he had completed in the operation I assisted with. ${ }^{4}$ That safety zone became known around the world, and is still known, as "Parkinson's triangle" (Figure 3). (Parkinson's triangle has its base located in the posterior half of the cavernous sinus, the apex of the triangle pointing anteriorly beneath [and lateral, as the wall slopes from a medial top to a more lateral bottom] to the trochlear and oculomotor nerves and above [and medial] to the first division of the trigeminal nerve as these three nerves approach each other within the front half of the cavernous sinus wall.)

Approximately 4 years later, Dr. Parkinson operated on the same patient again, but this time under deep hypothermia and cardiac standstill to arrest all bleeding. With the circulation stopped, he worked through the triangle that bears his name and was able to obliterate the fistula directly. Once more, symptoms and signs rapidly resolved, but the patient died a short time later from complications of the deep hypothermia.

Hugh Cameron was the second neurosurgeon at Winnipeg General, and he was the opposite of Dr Parkinson in every way. He was pleasant, easy-going, and affable, but not as experienced and obsessive a surgeon as his senior colleague. A pretty 22-year-old woman was referred to Dr. Cameron by an ophthalmologist because of headaches associated with papilledema. I can't remember what studies were done, but Dr. Cameron decided that she must have hydrocephalus and, as the neurosurgical intern, I helped him perform a posterior fossa craniotomy with the patient in the prone position. The cisterna magna was tight, but when the dura and arachnoid were opened and cerebrospinal fluid

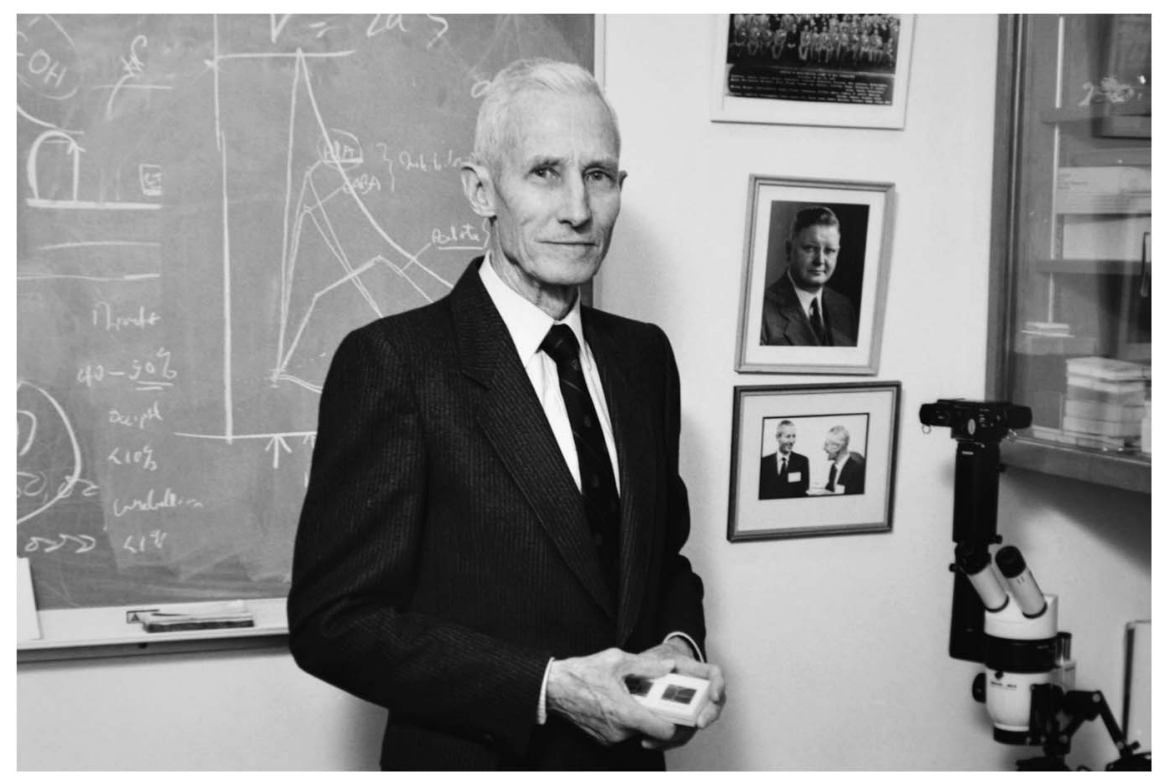

Figure 2: Dr. Dwight Parkinson in his office in the department of anatomy, University of Manitoba (after retirement from clinical practice), circa the late 1980s (photo courtesy of Dr. Garnette Sutherland). 


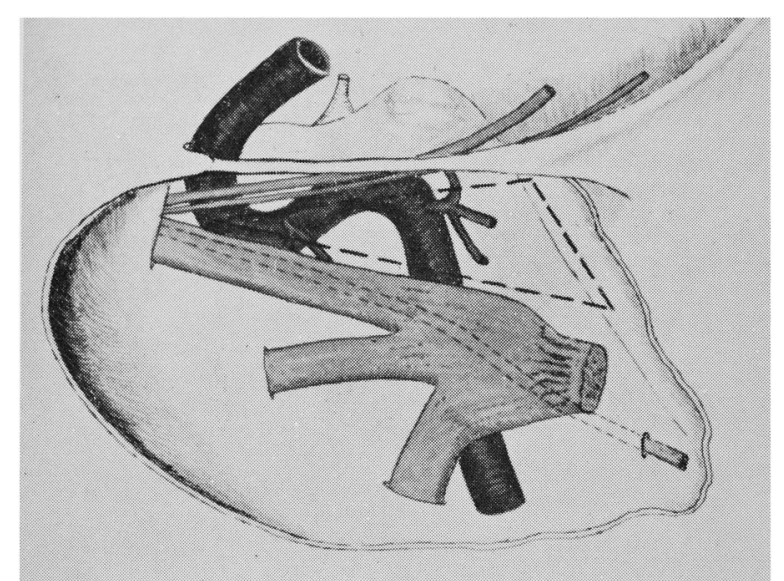

Figure 3: "Parkinson's triangle" of the cavernous sinus.

(CSF) allowed to escape the brain slackened and intracranial pressure seemed relieved. Dr. Cameron attempted to carry out a "Torkildsen shunt," which was a diversion of CSF from the right lateral ventricle into the cisterna magna opening we had created, using an implantable tube. (The ventriculoperitoneal shunt including a valve and silicone tubing used today was not introduced until the 1960s.) Our technology was crude and we only had a "red rubber straight urinary catheter" with a heavy wire stylet inside to insert into the right lateral ventricle through an occipital-parietal burr hole. Dr. Cameron couldn't pull the stylet out after he had sunk the catheter into the brain. He asked me to try but I couldn't retrieve it either. It was stuck, and so were we.

Dr. Cameron then decided that the cisterna magna was perhaps a congenital arachnoid cyst (such as a Dandy-Walker cyst) and that by deflating the "cyst" with our opening we had already treated the cause of the CSF obstruction and resulting raised intracranial pressure. After all, things seemed improved with the CSF drainage from the cisterna magna. He abandoned the idea of inserting a shunt, removed the catheter (with its stylet) from the ventricle, and we closed the wounds.

Later that evening, I was talking to Dr. Parkinson about a new case he was sending in to "casualty" (the emergency room) for admission and he asked me about Dr. Cameron's operation earlier that day. I told him about the diagnosis we had made and the failed shunt attempt. He gave a little grunt and advised me to keep a close watch on the patient postoperatively. There was no intensive care unit in those days and the patient had been sent up to the ward from the postanesthetic room. I checked on her several times through the evening until I left the hospital about midnight to get some sleep in our apartment next to the hospital.

At 7 AM, I got an urgent page and ran across the street to the hospital and up to the patient's room to find that the surgical and anesthetic residents were attempting to resuscitate her, but it was too late. I had to talk to her family, who graciously consented to a postmortem examination. Later in the autopsy room, the answer was revealed. She did have hydrocephalus, which was due to a small hemangioblastoma tumour in her midbrain that occluded the aqueduct. This is a very rare condition and the only treatment available, then and I imagine even now, would have been a successful shunt or some other means of diverting the CSF around the aqueduct of Sylvius. I realized that if we had been able to insert the shunt, her death might have been avoided, but nonetheless I felt as if I had been part of this girl's team of executioners.

\section{Part 2: General Practice in Saskatchewan}

I went out to Biggar, Saskatchewan, in July 1957 to do general practice with two general practitioners who had also graduated from the University of Manitoba, Drs. Alan Hooge and Laurie Dunbar. Biggar was Laurie's hometown and the senior Dunbar and the Hooge families were great friends, so the practice acted as a father and son clinic and I was the new guy in town. They treated me well, but it was up to me to build up my own practice to support my wife and me, so I cared for the doctors' patients only when they were away or sick. Dr. Hooge had been the sole doctor in the district during World War II; therefore, the entire community had been his patients during that time. Dr. Jerry Pinto was the fourth doctor in town. Jerry and I became good friends and my wife, Nina, and I found that we had a good deal in common with Jerry and his wife, Noma. It was small town life on the prairies more than a half a century ago.

One August day in 1958, two young farmers from the neighboring town of Perdue had spent the afternoon in the beer parlor celebrating one of the lad's impending nuptials. On the way home and at high speed, the driver failed to negotiate a curve in the highway and the vehicle rolled into the ditch. The driver was flung from the car and was lying on the ground unconscious while the passenger, the future groom, was lying on a nearby railway embankment 20 meters away. He'd been hurled out of the car and rolled across the ditch and up the railway embankment without striking a telegraph pole. I had been called to the scene but didn't really know what to do. People had stopped and gathered and expected me to take charge and do something. I took the driver's blood pressure, examined him neurologically because he was breathing on his own and didn't show any lateralizing signs, gave him an injection of "Coramine," a now-obsolete drug that acted as a stimulant and would likely do no harm. By this time, Biggar's Funeral Home "Schneider's" hearse-come-ambulance had arrived and we placed the patient gently onto a stretcher and then into the "ambulance." My attention then turned to the groom who was groaning, complaining of neck pain, but moving all limbs strongly. We put a collar on his neck and gently got him onto a stretcher and into the ambulance as well and both were rushed to St. Margaret's Hospital in Biggar. I followed behind in my car.

X-rays showed no obvious abnormalities. I called Dr. Joe Stratford, a neurosurgeon at the University Hospital in Saskatoon (our closest neurosurgery unit) and he advised me to make certain that the airways were secure and that probably I could look after the patients in Biggar. I managed to insert a "Guedel" oropharyngeal tube into my unconscious patient and admit him to hospital. About 3:00 AM, Sister Bezaire called me to report that this obtunded driver was becoming increasingly restless and cyanotic. I went up to the hospital to find him gasping and struggling for air in spite of oxygen. I wasn't confident in orally intubating the patient, but an airway and brain oxygenation was crucial for his survival. I performed a tracheostomy under local anesthetic and, with the sister's assistance and as soon as the trachea was opened and he inhaled air, his thrashing about settled and colour changed from blue to pink! I thought it best to transfer the patient the 60 miles to Saskatoon under Dr. Stratford's care 
and we sent him off immediately. We later learned that he had sustained a cerebral contusion with brain swelling but no intracerebral hematoma requiring surgery. After he was discharged home, his parents made a point of coming to thank me, as Dr. Stratford had generously informed them that I had saved their son's life.

But long before that, the groom was still in hospital complaining about his neck. We repeated the X-rays; his future bride happened to be our X-ray technician who had a keen interest in ensuring that the films were of the best possible quality, but no fractures or dislocations were apparent. On day 3 or 4 from admission, the groom announced that he had to go home and harvest his crop and threatened to sign himself out if I didn't approve. I could find no reason to keep him and off he went. Six weeks later, after the harvest, he returned to the office and reported that his neck still hurt "like a son-of-a-bitch" especially when he tried to turn it. There was still tenderness in the mid-line at the upper cervical region and limitation of cervical movement, but no neurological signs. We X-rayed him again and finally a fracture of the odontoid was clearly seen with some movement on flexion and extension views, indicating instability. I phoned Dr. Stratford and he advised that I might try applying a cervical cast for 3 months but if the fracture didn't unite the patient would need to have a surgical atlanto-axial (C1-C2) fusion.

For some strange reason, the notion that my patient might have to undergo a cervical fusion filled me with dread, and I resolved to attempt the conservative treatment. I had never applied a "spica" upper body cast before, but I think I had seen one during my internship and I found an illustration in a textbook. The cast consisted of a plaster of Paris jacket with a heavy plaster extension on its back attached to a crown of plaster. Diagonal side attachments flowed from the crown against the cheeks and parallel to the sternomastoid muscle to be fixed to the jacket at the level of the sternoclavicular joints. The ears were left open for hearing but the cast severely limited flexion, extension, and rotation of the neck while allowing full movement of the mandible for chewing and swallowing. God knows how anyone slept encased in such a contraption, but the human spirit is strong. And this abominable contraption had to be in place for a full 3 months and needed reenforcement once or twice during that period.

Our groom patiently endured this lengthy torture, however, and we were all very glad when the fracture had healed and the cast could be removed. Many years later, I talked to Joe Stratford about the case and he remarked that the cervical spica cast was abandoned because of its difficulty in application and the necessity for great endurance by the patient. I never again applied another cervical cast. By the time I was in neurosurgical practice, we used skull tongs and a Stryker bed in the 1960s and early 1970s; by the end of the 1970s, the halo-vest had become standard treatment for most cervical fracture dislocations.

These neurosurgical cases were all very challenging, interesting, and memorable. They have stayed with me over the years and contributed substantially to my formative interest in neurosurgery. The decision to train in the field, however, did not occur until November 1963.

\section{Part 3: The Gallie Course at the University of Toronto}

Three years of general practice in Biggar made me realize that I was fascinated by surgery and that I needed more training in a surgical specialty. I found that trauma was most challenging it seemed that orthopedics would provide a good base on which to launch a career in "traumatology." The Gallie surgical training course at the University of Toronto was highly regarded in Winnipeg; therefore, I decided to apply to that course.

Dr. Elmer James was head of orthopedics at the Manitoba Clinic in Winnipeg. Biggar was his hometown, with two of his sisters still living there, which accounted for his annual visit to the community. One of his sisters was a patient of mine, which gave me an opportunity to meet him during the summer of 1959 for the first time since my internship. I confided to him my plan to apply for training in orthopedics in Toronto. He asked me to contact him when we were in Winnipeg on our trip to the east. I did so and, subsequently, over lunch at the Manitoba Club, he told me that if I completed my orthopedic training they would offer me a position at the Manitoba Clinic and a staff appointment at the University of Manitoba. He also promised to provide me a letter of support to attach to my application to the Gallie Course, which had to be sent in a year in advance.

We drove to Toronto that July and I met my mother's first cousin, Dr. Ray Farquharson, who was at that time the professor of medicine at the University of Toronto. He told me he would be happy to provide me with a letter of recommendation that he thought would be helpful in my application to the Gallie Course in surgery. And so I was accepted into the Gallie training program in orthopedics, beginning in July 1961.

The first year was spent doing research at the Banting Institute under the supervision of Dr. Ian Macnab, an internationally known and respected orthopedist at the Toronto General Hospital. ${ }^{5}$ He was a man whose mind crackled with new and innovative ideas and whose wit and humour endeared him to patients and colleagues alike. Whenever he visited the laboratory, which was only once a month, he gave us several new plans and suggestions to be carried out, but it was difficult if not impossible for me to keep up and implement them all. By the end of the year, we had worked on 13 different projects! This was not a satisfactory situation but was made bearable by my collaboration with fellow researcher Dr. Marvin Tile (who subsequently became head of orthopedics at Sunnybrook Hospital), who provided support and friendship during a trying and frustrating time.

Probably the most notorious experiment that was done during my research time was an attempt to reproduce cervical whiplash injuries in animals. The experiment involved a drop down a vacant elevator shaft in the Banting Institute with wellanaesthetized animals held in an elaborate and ingenious cradle that allowed for only flexion and extension movement of the head and neck. The animals were "sacrificed" (the euphemism of the day) immediately and the cervical spines dissected and preserved for histopathological study. The slides showed that the least severe injury was a tearing of the anterior longitudinal ligament of the spine or even an avulsion of a small bit of bone from the inferior body of the vertebra above. The next degree of severity was a fracture through the vertebral body end plate; finally, the most severe injury was a subluxation of the vertebral bodies at the affected level. The pathology produced by these injuries was startling and demonstrated that whiplash was a real condition rather than an entity dreamed up by lawyers and denied by insurance companies (Figure 4). Orthopedists, neurologists, neurosurgeons, and physiatrists are used by the insurance companies over and over to justify denying compensation benefits 


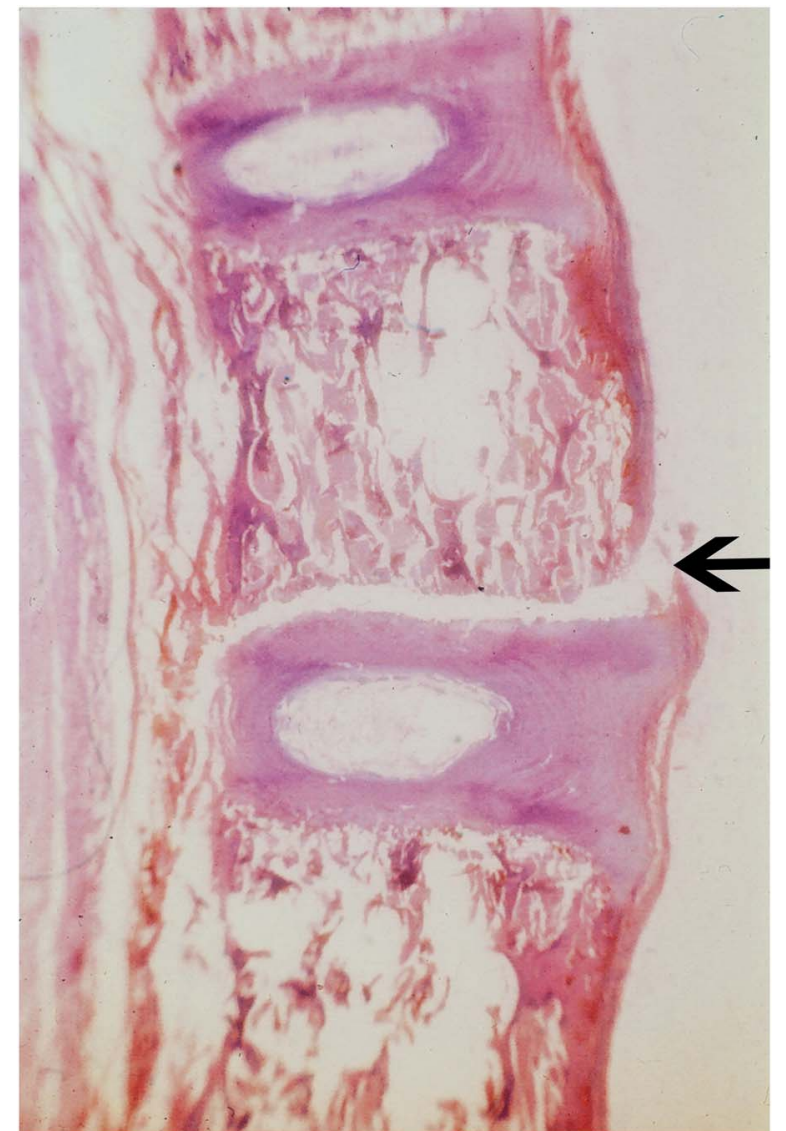

Figure 4: Hematoxylin and eosin section of the experimentally produced hyperextension animal cervical spine injuries showing avulsion of the anterior longitudinal ligament and fracture (arrow) through the intervertebral disk/vertebral body interface (photo from Graham Vanderlinden's personal records).

to plaintiffs whose lives have been wrecked by rear-end collisions. I found that I disliked using animals for experimentation but I had to for the sake of science and I did it. Dr. Macnab published our results as an abstract in The Journal of Bone and Joint Surgery, ${ }^{6}$ but I was disappointed that he did not acknowledge my contribution to the important scientific knowledge our hard work had achieved. I vowed that I would always recognize the contributions of students and junior colleagues to any work that I published in the future.

The first clinical rotation in my orthopedic training was 6 months of neurosurgery at the Toronto Western Hospital beginning January 1, 1963. I arrived at the hospital at 7:30 AM and reported to Dr. Andy Helmegyi, the outgoing senior surgical assistant. He had been up through the night with a young man named Dieter who had drunkenly crashed his car into a bridge abutment and had broken the windshield with his forehead. The patient was lying in the emergency department, semiconscious, waiting for Dr. J.F. Ross Fleming to come in and assess the situation. I had checked in with Ross a few days before to introduce myself and become familiar with this new hospital where I would be spending the next 6 months. I was thus somewhat prepared to go to work with this iconic character. At that time, Ross was only 37 years old but his premature balding made him appear older. He was perhaps 6 feet, 3 inches, tall with a long, thin face; lithe frame; and long limbs. Ross had boundless energy and stamina, a keen intellect, and a surgical technique that was exceedingly meticulous. When complications arose during surgery, he often became angry and demanding and more than one scrub nurse fled the O.R. in tears but later received flowers from a contrite Dr. Fleming.

Ross was standing over the unfortunate Dieter in the emergency department when I arrived. The Glasgow Coma Scale had not yet been invented, or had not been in use beyond the Clyde, and all we could do in our assessments of the level of consciousness was to describe a patient's reaction to a vocal or painful stimulus and describe him or her as being conscious, stuporous, or comatose. The Glasgow Coma Scale was devised by Bryan Jennett and Graham Teasdale, professors of neurosurgery at the University of Glasgow in the mid-1960s and was instantly recognized the world over as the standard of coma assessment and a major advance in head injury care. ${ }^{7}$ I can't remember Dieter's level of consciousness, but he was responding to painful stimulation, was restless, and had lacerations of his forehead and compound comminuted fractures of the frontal bone. Ross pointed out that the bloody material he had wiped off the patient's brow was brain tissue and therefore we would have to operate and repair the damage. The OR was alerted, the patient was transported and anaesthetized, and we began the surgery about 9:00 AM, finishing about 4 hours later. Ross was in an expansive mood and he paid for our New Year's turkey dinner in the hospital cafeteria. Thus began my first 6 months of clinical neurosurgical training as well as a professional collaboration with Ross that extended over the next 24 years.

Toronto Western Hospital was on the lookout for a replacement for Dr. William Keith, who had founded the divisions of neurosurgery at both the Toronto Western and Sick Children's Hospitals in $1937 .{ }^{8}$ By 1963, Bill Keith was winding down his practice and indeed he had been suffering from a depression for several years before my arrival. Towards the end of my rotation, both Bill and Ross told me that they believed that I would make a good neurosurgeon if I switched from orthopedics. I was flattered by this confidence and told them that I would think about their offer, but wanted to carry on with the next scheduled stint of a year's surgical training at "Sick Kids" before making up my mind. They agreed and thought it would be wise to obtain an assessment of my abilities at The Hospital for Sick Children by Dr. Bruce Hendrick, the chief of neurosurgery, as well as the input of the other surgeons there. I spent September and October as a senior on the paediatric neurosurgical service with Dr. Robert (Bob) Elgie, the resident. I loved the neurosurgical work, but when November and December's rotation in orthopedics under Dr. Robert Salter came along, I found that I disliked the mechanical nature of orthopedics. The contrast between orthopedics and neurology was like night and day; I therefore I decided to switch after talking it over with my wife. I spoke to Bill Keith and told him of my decision and he immediately picked up the phone and called Dr. Fred Kergin, the surgeon-in-chief and head of the Gallie training program who made an appointment to see me in his office in the Banting Institute. Dr. Kergin was a very strict disciplinarian and an autocrat with a penchant for insulting any trainee who had the temerity of having graduated from what he considered a second-class medical school such as the University of Manitoba. I was scared to death when I attended that meeting with Dr. Kergin, but all he said was that it was too bad I had not made 


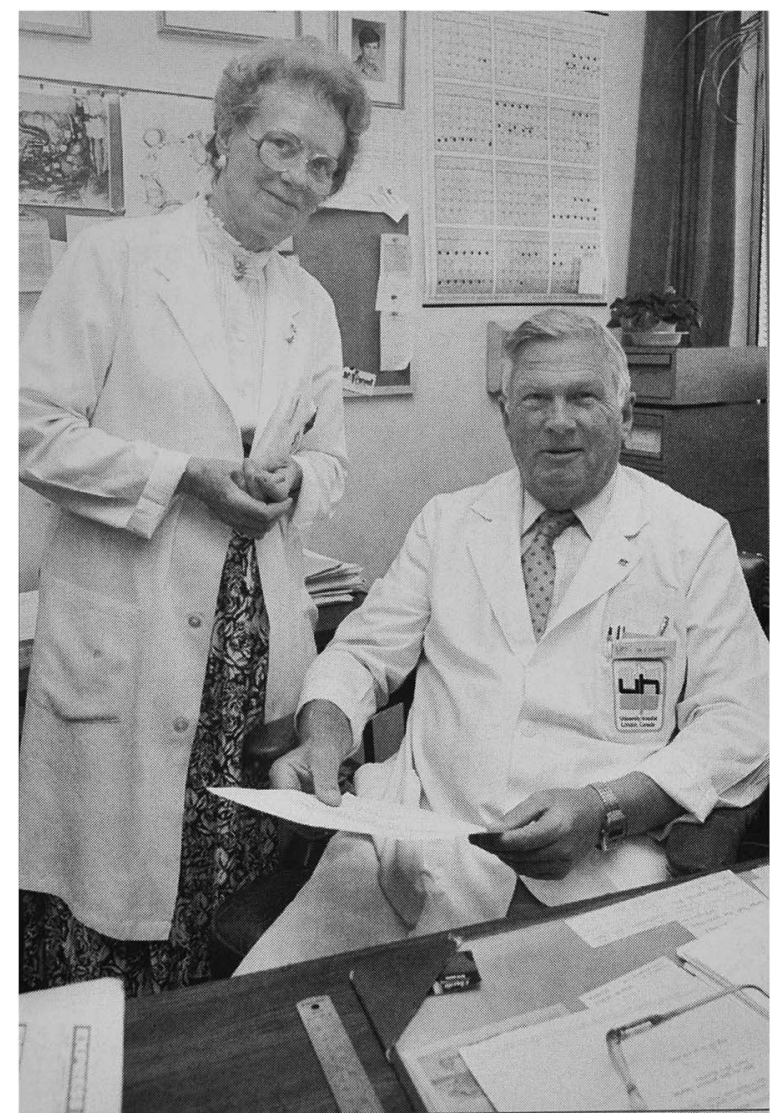

Figure 5: Dr. Charles Drake with his secretary Ms. Dorothy McManus, circa early 1980s (photo from Graham Vanderlinden's personal records).

up my mind a couple of weeks sooner for they had already chosen the candidate for the neurosurgical program, Skip Peerless. They would have to make other arrangements for me. Little did I know that the other arrangements were to train with the famous Dr. Charles Drake in London, Ontario (Figure 5).

\section{Part 4: Neurosurgical Training At The University of Western ONTARIO}

Dr. Drake had trained under Drs. Kenneth McKenzie (Canada's first full-time neurosurgeon) and Harry Botterell at the Toronto General Hospital. ${ }^{9,10}$ The young Drake's intellect, energy, innovative ability, and hard work had become legendary. He had declined an invitation to join the Toronto General Hospital staff and elected to return to his alma mater and form a neurosurgical service in London. He had published scientific articles on a number of topics, but it was his pioneering work on the treatment of basilar aneurysms that had captured the world's attention. ${ }^{11}$ When I began 18 months of training with him on January 1, 1965, he had already operated on eight basilar aneurysms; by the end of my tenure, I had assisted him with six more. Dr. Drake began to use loupes in 1965 (when he was 45 years old and likely developing presbyopia), but of course his assistant had to operate with the naked eye. I clearly recall Charlie introducing me to Dr. Ted Kurze, then chairman of the department of neurosurgery, Los Angeles Medical Center and the University of Southern
California, who had first introduced the binocular operating microscope to clinical neurosurgery in $1957 .{ }^{12}$ By this time, Dr. Kurze had been using the microscope for 8 or 9 years and was very impressed with the results. He said that operating with 10-power magnification was like "the rapture of the deep," as a whole new world had opened up to him. He urged Charlie to obtain an operating microscope as soon as possible. After I had begun practice, we got our first Zeiss microscope at the Toronto Western Hospital in 1968-69 and indeed it was thrilling to use. My greatest realization was that when the eye saw and the brain perceived at the higher magnification, the motor control was likewise enhanced and much finer work was then achieved. Today, it would be considered malpractice to attempt to clip an aneurysm or dissect a tumour off a cranial nerve using the naked eye alone, yet that was routine practice during much of my neurosurgical training.

The development and progress of diagnostic imaging in the neurosciences and through my career has been fantastic. When I was a resident, it fell to the neurological and neurosurgical seniors to carry out percutaneous carotid artery punctures and perform the angiograms in the OR, where the radiologist or radiology technician operated the $\mathrm{X}$-ray machine and pulled out the X-ray films as they were being exposed. Dr. John Allcock in London, Ontario, was so skilled that he routinely did percutaneous vertebral arteriograms (few others could do this), and thus uncovered those basilar artery aneurysms for which Dr. Drake pioneered the surgical treatment. These techniques, however, were soon superseded by the femoral artery catheterizations using the Seldinger technique.

Pneumoencephalograms were pure torture but were still being done, and some neurologists sadistically ordered them on young patients who persistently complained of headaches without any other neurological signs. They considered that these people were only expressing behavioral or neurotic symptoms that should be gotten over with the experience of a "real" headache that a pneumoencephalogram would produce. These tests were referred to as "punitive air studies"!

Ventriculograms were done initially in the OR; a parietaloccipital burr hole was performed, a cannula inserted into the lateral ventricle, and radio-opaque liquid injected while the patient was in a seated position with the head tilted forward. The patients were then taken to the radiology department where they were seated in a special chair that somersaulted them around causing the "dye" to roll back across the top of the ventricles and through the Foramen of Munro and finally into the third and fourth ventricles. This study was indicated when an intracranial mass was obstructing the ventricular system and causing raised intracranial pressure, hydrocephalus, and papilledema, in which case an air study would be contraindicated.

Radio-isotopic studies were begun during my residency, but the technology was very basic and the results quite imperfect when compared with later imaging techniques. The images obtained after running a Geiger counter over a patient's head following the intravenous injection of an isotope were grainy as the pixels were relatively large but it still gave us a much clearer idea as to the location of a mass lesion than did the neurological examination.

Computed axial tomogram scans were invented in Britain and developed by the Electrical Music Institute (The Beatles' recording company) in the late 1960s and in fact were initially known as EMIs. The first EMI machine in Canada was obtained 
by the Montreal Neurological Institute and I saw my first computed axial tomogram scan image at a Canadian Neuroscience meeting in the early 1970s. Our first computed tomography machine was installed at Toronto Western about 1976, and it was a great leap forward in diagnostics. About 5 years later, our first magnetic resonance imaging machine was installed; they are now the standard of diagnosis. Fortunately, the air studies, ventriculograms, and spinal myelograms became obsolete and drifted into history. I do regret that our young colleagues will not even know what these studies were.

There were so many memorable events from my neurosurgical training that it is difficult to single out the most impressive, but two cases during my 18 months with Dr. Drake were very dramatic in their presentation and final result.

The first occurred in the fall of 1965, when I had been Dr. Drake's resident for about 9 months. A mentally challenged young man, who came from a family that was similarly afflicted, presented in the emergency room of Woodstock General Hospital in southwestern Ontario. He had a history of progressively worsening headache, erythema, and puffiness over the forehead; 2 days of fever; and finally an obtunded level of consciousness. Skull X-rays revealed a "moth-eaten" appearance of the frontal bones and opacification of the frontal sinuses. I saw him in the emergency room of London's old Victoria Hospital (now defunct) and found that he was one of the sickest patients I had ever seen. The clinical diagnosis was apparent because he had developed an epidural empyema secondary to osteomyelitis of the frontal bone caused by chronic frontal sinusitis. This condition was rare by the latter half of the 20th century because most people in Ontario would have consulted a physician and been treated long before the pathological process had developed to that extent. He was prepared for emergency surgery that consisted of turning a bifrontal craniotomy flap, leaving the bone out to be autoclaved (and later replaced). Purulent material was syringed from the epidural space; the dura was opened and also drained of pus. Drains from the subdural and epidural spaces were established to collect residual pus. I can't remember the organism, but it was likely a pneumococcal bacterium that was sensitive to antibiotics, which we administered intravenously in high doses.

The patient was transferred to the isolation ward that consisted of about six beds located on the third floor of an older wing that could only be accessed by a very slow, creaky freight elevator, although one could exit the unit by a back staircase. The following morning the patient began to have generalized seizures, and I was summoned from the second-floor OR to administer intravenous diazepam, which controlled the seizures temporarily while the phenytoin came up to therapeutic levels. Each time the seizures began, I was called out of the OR to administer diazepam because the nurses said they were not allowed to give these drugs intravenously. I asked the pharmacy to mix up a 50-ml syringe of Valium, inserted the needle into the intravenous tubing, and asked the nurses to inject $2 \mathrm{ml}$ whenever the patient began to have a fit. No, apparently they weren't allowed to do that either. I talked to the anesthesia staff and they suggested using a machine available in their department whereby the 50-ml syringe could be clamped in and calibrated so that the press of a button turned on the machine and the proper dose of antiseizure medication was automatically delivered to the intravenous tubing. The nurses were allowed to press the button and effectively treat the seizures. The patient eventually made a full recovery, but I was always convinced that if it wasn't for a little ingenuity on the part of the medical staff, the strictures that the heads of the nursing department placed on their members might have led to the demise of this unfortunate young man.

This is one example of how reactionary the senior nursing staff had become, much to the frustration of doctors and many of the young, bright nurses who eventually changed the culture of their profession. They gradually modernized, and this led to the development of nurse practitioners, physician assistants, and the highly skilled workers in our intensive care units.

The second memorable case occurred on June 18, 1966, the last Saturday night of my tour of duty at the Victoria Hospital in London, Ontario. About 5:30 PM, a 5-year-old London girl named Suzie was playing alone in the family garage and, although we didn't know it at the time, must have fallen and struck the right side of her head on some solid object. She was probably unconscious for a short time but regained consciousness and responded when her mother called her in for supper. The mother was puzzled by her daughter's apparent listless and fussy approach to the meal because Suzie was always a lively, chatty child with a generous appetite especially after an afternoon's play in the fresh air. Suzie complained that her head hurt and when she began to vomit her mother became concerned and called their pediatrician. He knew the child and that the family didn't call unless something significant was occurring. He advised them to take Suzie to the emergency department of Victoria Hospital and he would come down to see her there later. They arrived in emergency about 7:15 PM and were greeted by a waiting room full of sick, frustrated, impatient patients and their families.

One should avoid at all costs requiring emergency services in the first week after June 15 because that is the date when the teaching hospitals are restaffed by a new group of interns who have just finished their fourth-year examinations and are inexperienced in the practical application of all that knowledge. At 8:00 PM, the exhausted interns, who had been working slowly and methodically all day, came to the end of their shift, leaving a backlog of some 20 patients for the night shift. The night shift rotation was taken over by a pediatric senior who had just completed 2 years of research and whose clinical skills were rather rusty. The head nurse was carrying out a triage when she finally came across Suzie and her parents. There was nothing the matter with her nursing skills or with her intuition. She didn't like the looks of the child who was pale, vomiting, and complaining of headache when she wasn't sleeping. She informed the new senior that he should see this patient immediately and, knowing her competency, he followed this advice. He really didn't know what was going on with the child in view of the sketchy history and therefore sent her off to the radiology department for a skull X-ray at 8:20 PM. This bought some time until the expected arrival of the pediatrician. The pediatrician didn't see anything on the poorly exposed X-rays and decided to take Suzie back for another film in the hope that something would turn up or at least come to mind. About 9:00 PM, in the radiology department, Suzie stopped breathing and began to exhibit the cyanosis of apnea. She was dying.

That Saturday night, I had been invited to Bob and Mary Barr's home for dinner about 7:00 PM; Lorne Amacher (the level 3 neurosurgical senior) and his wife were expected to join us for a pleasant evening of fellowship and conversation. Bob Barr was training in hematology at the Victoria Hospital, whereas his 
brother, Hugh, was training in neurosurgery in Toronto; they were sons of the illustrious Murray Barr of Barr-body fame and professor of neuroanatomy at the University of Western Ontario. Bob and his wife lived in one of the houses owned by Victoria Hospital at the end of the street that bordered the hospital. They were only half a block away, so we were permitted to spend time there and still be on call. At 9:00 PM, we had finished dinner and Bob and I were just settling down in the living room for a postprandial cigar when the phone rang for me. The hospital operator said there was an emergency call from the radiology department and that I better get over there quickly for it sounded like the "real deal." I dropped the phone and ran down the front steps, nearly bowling over the Amachers on their way to the Barr's soiree. There was a back door to the X-ray suite about 50 yards away and I sprinted through and arrived at the scene in about 30 seconds.

Here was this still, little child with cyanotic lips lying like a ghost on a large gurney with a panicked pediatrician trying to compress her chest while the nurse and radiology technician looked on helplessly. A quick assessment revealed dilated pupils, apnea, and no movement in response to pain. I said rather rashly and ominously, "She has gone! What the hell has happened here?" They gave me a quick summary of what little they knew and thought she must have suffered a head injury. I placed my hands on either side of her head and felt the scalp swelling on the right that likely indicated an underlying skull fracture. The stethoscope revealed a rapid but barely discernable heartbeat. I gave her mouth-to-mouth respiration and she pinked up. There was a chance that she had sustained an epidural hematoma beneath the skull fracture and that prompt action might still save her. I inserted a pharyngeal airway and asked the pediatrician to pump oxygen via face mask, ordered the technician to call the OR and tell them that we were on our way, and told the nurse to summon the elevator while I pushed the stretcher down the hall running, with the others trying to keep up. There was no time to talk to the parents who waited forlornly worrying about their precious daughter and quite ignorant of the flurry of activity her condition had inspired.

Fortunately, the OR was quiet, and the nursing team was sitting in their lounge enjoying the Saturday evening break. The team was one of our best and it had the OR ready and instrument bundles open in 3 minutes. I did a quick wash of my hands and Suzie's scalp, donned a pair of gloves and, without any anesthetic, incised the scalp and put in a burr hole. The black, clotted epidural blood spurted out and a sense of relief and even elation came over us as the child began to move and breathe with the release of the intracranial pressure. Only then were we able to summon the on-call anesthetist, do a proper scrub, prep, and drape while one of the nurses held Suzie down so she wouldn't fall off the OR table. Once Suzie was anaesthetized, the burr hole was extended into a craniotomy and the entire clot removed, the craniotomy closed, and a full head dressing applied, as was the custom in those days. Suzie was taken to the recovery room and I could finally go down to the emergency waiting room to speak to the parents, who were much relieved to learn what had happened to their daughter. As usual, I tempered my cautiously optimistic prognosis with the admonition that the final outcome was still unknown. In neurosurgery, it is wise to employ the adage that we hope for the best but have to be prepared for the worst.

The next morning, Sunday, I started my rounds in the recovery room, where the nurses had been monitoring our wee patient all

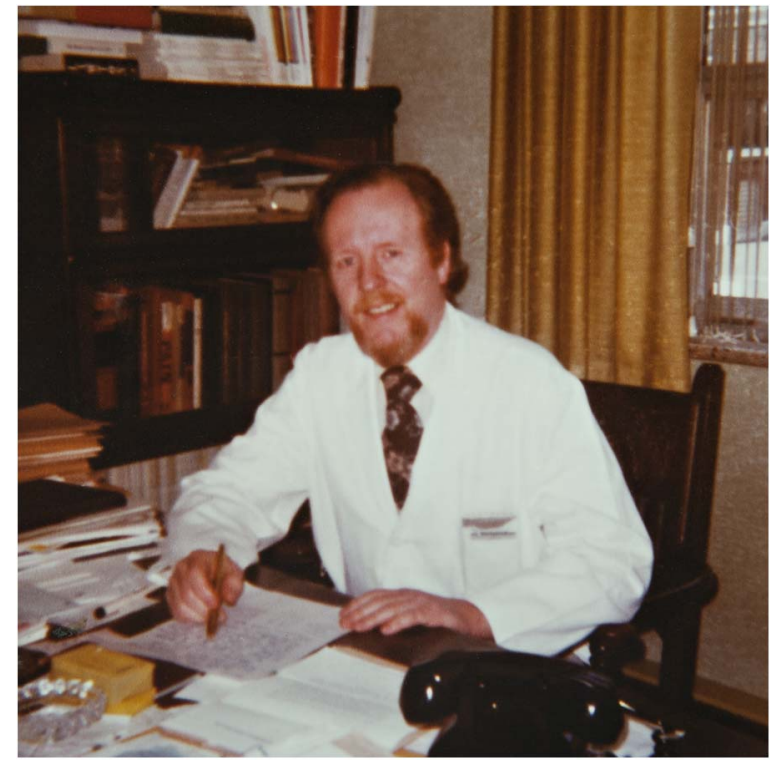

Figure 6: A picture of Graham Vanderlinden in his old office on Leonard Street (Toronto Western Hospital), taken in the mid-1970s or early 1980s and shows hair on top as well as the beard.

night without finding it necessary to call me. Suzie was lying in a crib with her eyes closed, looking fragile and vulnerable, with the large head dressing accentuating her tiny size. I gave her a shake and called her name. Without opening her eyes she said rather irritably, "I want to see grandma." It was a real thrill to realize that she was fine and everything would turn out well. A magnificent way to complete a neurosurgical residency! There was no way, however, that such an accomplishment would go to my head, for when I told Dr. Drake about the case next day his laconic comment was "you were lucky" (Figure 5).

\section{Conclusion}

My advice for residents and young faculty as they embark on a career in neurosurgery is as follows.

1. Be honest!

2. Don't be afraid to question orthodoxy.

3. Seek new ways to solve ongoing problems.

4. Strive to find better methods to do operations and procedures: try to think "outside the box."

5. Always consider the suggestions of colleagues, juniors, and students. Remember, some of them are smarter than you are.

6. Keep a record of your cases and periodically review your results.

7. Enjoy the ride when you can. Neurosurgery is the Magnificent Obsession (Figure 6).

\section{ACKNOWLEDGMENTS}

I thank Max Findlay for his encouragement and valuable editing contributions to this paper, as well as the expert assistance provided by Shelan Beatty in the preparation and submission of this manuscript.

\section{Disclosures}

The author does not have anything to disclose. 


\section{REFERENCES}

1. Parkinson D. Collateral circulation of the cavernous carotid artery: anatomy. Can J Surg. 1964;7:251-68.

2. Parkinson D. Early history of neurosurgery in Manitoba: threads in the tapestry of world neurosurgery. J Neurosurg. 1995;82: 900-6.

3. https://www.societyns.org/society/bio.aspx? MemberID=10694

4. Parkinson D. A surgical approach to the cavernous portion of the carotid artery. Anatomical studies and case report. J Neurosurg. $1965 ; 23: 474-83$.

5. http://www.scientificspine.com/who-is-who/ian-macnab.html

6. Macnab I. The pathology of experimentally produced hyperextension cervical injuries. Presented at the American Academy of Orthopedic Surgery, Chicago, January 1963. Acceleration injury of the cervical spine. J Bone Joint Surg. 1964;46A: 1797.

7. Teasdale G, Jennett B. Assessment of coma and impaired consciousness. A practical scale. Lancet. 1974;13:81-4.

8. Fleming R. In memoriam: William Strathearn Keith 1902-1987. Can J Neurol Sci. 1988:165-7.

9. Findlay JM. Neurosurgery at the Toronto General Hospital 1924-1990: part 1. Can J Neurol Sci. 1994;38:146-58.

10. Ferguson GG. In memoriam: Charles G Drake. Can J Neurol Sci. 1999;26:330.

11. Drake CG. The surgical treatment of aneurysms of the basilar artery. J Neurosurg. 1968;29:43646.

12. Kurze T. Microtechniques in neurological surgery. Clin Neurosurg. $1964 ; 11: 128-37$. 